\title{
An evaluation of the rosette inhibition test in Crohn's disease
}

\author{
J. R. CLARKE, E. R. RICHENS, M. J. WILliAMS, K. R. GOUGH, AND \\ R. J. ANCILL
}

From the Department of Clinical Investigation, Royal United Hospital (North), Bath

SUMMARY Serial rosette inhibition tests were performed on nine patients with Crohn's disease undergoing immunosuppressive therapy in an attempt to estimate the minimum amount of drug necessary to maintain immunosuppression. The rosette inhibition titre was found to be higher in immunosuppressed patients than in normal subjects. However, there was no consistent correlation of the rosette inhibition titre with the degree of activity of the disease. The test is therefore not sufficiently discriminative to be used as a basis on which to control drug dosage.

A high proportion of human lymphocytes will react with sheep red cells to form spontaneous rosettes (Jondal, Holme, and Wizgell, 1972; Chapel, 1973), which have been shown to be inhibited by high dilutions of antihuman lymphocyte globulin (Bach, Dardenne, Dormont, and Antoine, 1969). A test in vitro based on this inhibition of spontaneous rosette formation was first described for mouse lymphocytes (Bach and Antoine, 1968) and then modified for human lymphocytes (Munro, Bewick, Manuel, Cameron, Ellis, Bolton-Jones, and Ogg, 1971). It has been suggested that this test is a measure of the immunosuppression of a patient's lymphocytes, and that a decrease in inhibitory concentration is associated with rejection in transplantation (Bewick, Ogg, Parsons, Snowdon, and Manuel, 1972; Cullum, Bewick, Shilkin, Tee, Ayliffe, Hutchinson, Laws, Mason, Reid, Hugh-Jones, and Macarthur, 1972).

The aetiology of Crohn's disease is still uncertain but much attention is at present directed to the possibility of an immunological origin or of a secondary immune response as an important factor in its pathogenesis. Suppression of disease activity is sometimes achieved by azathioprine and steroids (Willoughby, Kumar, Becketts, and Dawson, 1971) and in view of the controversy with regard to this treatment (Rhodes, Bainton, Peck, and Campbell, 1971) it was decided to investigate the use of the rosette inhibition test in assessing the state of immunosuppression of patients treated with these drugs.

Received for publication 20 June 1974.

\section{Materials and Methods}

\section{ROSETTE INHIBITION TEST}

The technique used was based on that originally described by Munro et al (1971). Lymphocytes were obtained from $10 \mathrm{ml}$ samples of heparinized peripheral blood by spinning over a Ficoll triosil column (Harris and Ukaejiofo, 1969). The lymphocyte suspension was washed three times in phosphate-buffered saline, pH 7.35 (PBS), and adjusted to $2 \times 10^{6}$ cells per ml in either PBS or Hank's solution. A $100 \mu$ l sample of this suspension was added to serial dilutions of antilymphocyte globulin from $1 / 4000$ to $1 / 512000$ in $250 \mu l$ salt solution. A $100 \mu 1$ sample of this suspension was placed in disposable plastic tubes with $50 \mu \mathrm{l}$ of a $1 / 6$ dilution of preserved guinea pig complement (Wellcome). The tubes were then incubated at $37^{\circ} \mathrm{C}$ for 90 minutes. A red cell suspension was prepared from fresh sheep red cells which had been washed three times in PBS at a final dilution of $1 / 50$, and $100 \mu l$ of the suspension added to each tube and the tubes were spun at $200 \mathrm{~g}$ for five minutes. The tubes were then placed on a rotating disc at $28 \mathrm{rpm}$ to re-suspend the cells and rosettes. The preparation was immediately counted for lymphocyte and rosette content on a Fuchs Rosenthal chamber. The number of rosettes per 1000 lymphocytes at each antilymphocyte globulin dilution was plotted to produce a rosette inhibition curve. The rosette inhibition titre is taken at the point of the curve where there is a $25 \%$ reduction in the number of rosettes compared with a control sample with no antilymphocyte globulin. 
The reciprocal of this titre is referred to as the minimum inhibitory concentration (MIC). It is known that in immunosuppressed patients the curve moves to the right with a consequent rise in MIC.

\section{PATIENTS AND CONTROLS}

Nine patients with Crohn's disease in various states of disease activity were tested at intervals. The diagnosis was confirmed on clinical, radiological, and histological evidence in all except one patient in whom typical Crohn's disease of the terminal ileum was found but was not resected at cholecystectomy. The group comprised four females and five males. Their ages ranged from 16 to 71 years (mean 46) and length of history from one to 22 years (mean 8.3).

Twenty-three healthy subjects were also studied, these being proportionally age- and sex-matched with the Crohn's disease group.

The disease was judged inactive if a patient had none of the following clinical features at the time of testing: weight loss, diarrhoea, abdominal pain, or fever. A patient with one or more of these symptoms was classed as active.

\section{Results}

In the 23 normal subjects tested by the rosette inhibition test, the mean MIC for the group was $24.3 \pm$ $4 \cdot 1$ (SD), the range being $16 \cdot 1$ to $32 \cdot 5$.

Age was found to affect the endpoint slightly in that the MICs for the $15-30$, the 31-50, and the 51$70+$ age groups were found to be $23.9 \pm 4.4(22$ observations), $23.8 \pm 4.1$ (31 observations), and $26.3 \pm 2.8$ (19 observations) respectively. No difference was found between the sexes, the MIC for males being $24.0 \pm 4.1$ and for females $24.9 \pm 3.8$.

Where PBS was used in the incubation medium (30 cases) the percentage of rosette-forming cells was $25.1 \pm 9.9$ and where Hank's solution was used (37 cases) this number fell to $11 \cdot 2 \pm 8 \cdot 1$. However, the MIC was not affected by the percentage of rosette-forming cells. With PBS the MIC was $24 \cdot 8 \pm$ $3 \cdot 2$ and with Hank's solution it was $24 \cdot 1 \pm 4 \cdot 7$. This difference is not significant $(P>0 \cdot 10)$.

The patients under study were divided into groups according to their clinical condition and whether or not they were receiving immunosuppressive therapy. The results are summarized in the table: they represent the aggregate results of sequential testing on the nine patients. When not on immunosuppression, those patients in an active phase of the disease show a significantly lower MIC $(P<0.001)$ than those patients with inactive disease who give results close to the normal range. After a short period (less than four days) on immunosuppression, high MIC values

\begin{tabular}{llll}
\hline $\begin{array}{l}\text { Period of Immu- } \\
\text { nosuppression }\end{array}$ & $\begin{array}{l}\text { Disease } \\
\text { Activity }\end{array}$ & $\begin{array}{l}\text { No. of } \\
\text { Observations }\end{array}$ & $\begin{array}{l}\text { Mean MIC } \\
\text { SD }\end{array}$ \\
\hline Nil & $\begin{array}{l}\text { Active } \\
\text { Inactive }\end{array}$ & 24 & $13 \pm 10$ \\
Less than 4 days & Active & 10 & $31 \pm 13$ \\
Inactive & -18 & $138 \pm 144$ \\
More than 4 daysActive & Inactive & 17 & $189 \pm 138$ \\
& 17 & $140 \pm 166$ \\
\hline
\end{tabular}

Table Mean MICs $( \pm I S D)$ obtained from groups of Crohn's patients in various stages of immunosuppressive therapy and clinical activity of disease

were obtained in the patients tested, all of whom remained in an active phase at this time. Within four days' treatment MIC rises significantly $(P<0.001)$. This difference becomes more marked with increasing length of immunosuppression. After more than four days' treatment no significant difference in MIC is apparent between the active and inactive groups $(P>0 \cdot 1)$.

Immunosuppression appears to be the critical factor affecting the MIC, as little difference was seen between the total results obtained from active (92.5 $\pm 127)$ (52 observations) and inactive $(98 \pm 139)$ (28 observations) groups of patients. This is effectively illustrated in the case of $\mathrm{HI}$, shown in the figure.

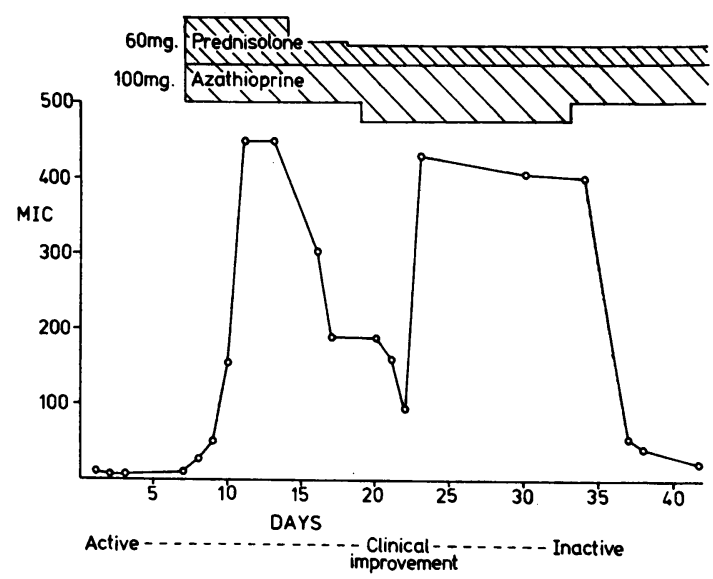

Fig Case HI: Changes in minimum inhibitory concentration while on treatment with prednisolone (25 to $60 \mathrm{mg}$ daily) and azathioprine (100 to $150 \mathrm{mg}$ daily).

\section{Discussion}

There have been conflicting reports on the rosette inhibition test in predicting the activity of autoimmune disease and the effect of immunosuppressive therapy in a variety of conditions. Munro et al (1971) 
have shown it to be of predictive value in the detection of renal allograft rejection. Bewick et al (1972) have also used the test on renal allograft patients on immunosuppressive therapy. They claim an improvement at three months in these patients in comparison with similar patients not monitored by the rosette inhibition test, and suggest that the improvement was due to a reduction in the number of rejection episodes. This suggestion has not been confirmed by later work (Harris and Ukaejiofo, 1969).

The technique has also been used as a measure of the period of immunosuppression following severe burns (Wood and Grey, 1973). The test did not appear to be a direct measure of immune reactivity.

Finally, Farid, Munro, Rowe, and Volpe (1973), studying patients with Graves' disease and Hashimoto's thyroiditis, showed a useful correlation of the MIC with clinical activity of disease. Patients in remission or treated with ${ }^{131}$ I or antithyroid drugs had normal results.

The test is relatively simple to perform and a result may be obtained in four hours. As it might have proved useful in correlating clinical response with immune status, it seemed appropriate to evaluate its use in cases of Crohn's disease on immunosuppressive therapy.

The results obtained demonstrate that the MIC correlated with the immunosuppressive potency of sera from patients on azathioprine. However, there was no consistent correlation with the degree of activity of the disease. This latter factor continues to be the determining factor in deciding a change of dose in managing these patients. Thus, despite the fact that the test clearly differentiates between groups of patients receiving immunosuppression and those not so treated, this differentiation in itself is not sufficient to be of practical value in controlling immunosuppressive dosage in Crohn's disease.

\section{References}

Bach, J. F., and Antoine, B. (1968). In vitro detection of immunosuppressive activity of anti-lymphocyte sera. Nature (Lond.), 217, 658-659.

Bach, J. F., Dardenne, M., Dormont, J., and Antoine, B. (1969). A new in vitro test evaluating anti-lymphocyte serum potency. Transplant. Proc., 1, 403-406.

Bewick, M., Ogg, C. S., Parsons, V., Snowdon, S. A., and Manuel, L. (1972). Further assessment of rosette inhibition test in clinical organ transplantation. Brit. med. J., 3, 491-494.

Chapel, H. M. V. (1973). The effects of papain, trypsin and phospholipase A on rosette formation. Transplantation, 15, 320-325.

Cullum, P. A., Bewick, M., Shilkin, K., Tee, D. E. H., Ayliffe, P., Hutchinson, D. C. S., Laws, J. W., Mason, S. A., Reid, L., Hugh-Jones, P., and Macarthur, A. M. (1972). Distinction between infection and rejection in lung transplantation. Brit. med. J., 2, 71-74.

Farid, N. R., Munro, M. E., Rowe, V. V., and Volpe, R. (1973). Rosette inhibition test for the demonstration of thymusdependent lymphocyte sensitization in Graves' disease and Hashimoto's thyroiditis. New Engl. J. Med., 289, 1111-1116.

Harris, R., and Ukaejiofo, E. O. (1969). Rapid preparation of lymphocytes for tissue typing. Lancet, $2,237$.

Jondal, M., Holm, G., and Wizgell, H. (1972). Surface markers on human T.- and B-lymphocytes with sheep red blood cells. J. exp. Med., 136, 207-215.

Munro, A., Bewick, M., Manuel, L., Cameron, J. S., Ellis, F. G. Bolton-Jones, M., and Ogg, O. S. (1971). Clinical evaluation of a rosette inhibition test in renal allotransplantation. Brit. med. J., 3, 271-275.

Rhodes, J., Bainton, D., Peck, B., and Campbell, H. (1971). Controlled trial of azathioprine in Crohn's disease. Lancet, 2, 12731276.

Willoughby, J. M. T., Kumar, J. P., Beckett, J., and Dawson, A. M. (1971). Controlled trial of azathioprine in Crohn's disease. Lancet, 2, 944-946.

Wood, R. M. F., and Grey, A. C. (1973). Evaluation of rosette inhibition test in renal allotransplantation. Brit. med. J., 4, 6-9. 